\title{
GLOBALIZAÇÃo, SERVIÇOS DE SAÚDE E DIREITO INTERNACIONAL
}

\author{
GLOBALIZATION, HEALTHCARE E INTERNATIONAL LAW W*)
}

Antonio Gelis Filho ${ }^{(* *)}$

\section{RESUMO}

Ao longo da última década, uma série de fatores sociais, econômicos e políticos, mais conhecida como "globalização", vem determinando modificações no cenário internacional e nos contextos nacionais. Como qualquer outra área da atividade econômica e social, os serviços de saúde estão expostos a transformações ainda não totalmente previsíveis. A sede principal de debates sobre o assunto ainda está indefinida, com marcante atividade no âmbito da Organização Mundial do Comércio, aparentemente sem oposição aberta pela Organização Mundial da Saúde. Os desenvolvimentos dos próximos anos poderão criar uma nova estrutura para o setor, devendo portanto serem precedidos por amplos debates envolvendo representantes de todos os interessados.

\section{Palavras-chave}

Globalização, Serviços de Saúde, OMC, OMS, Direito Internacional.

\section{ABSTRACT}

In the last decade, a series of social, economic and politic facts, better known as "globalization", has determined changes in the international sphere and also in the national level. As any other field of economic and social activity, healthcare is exposed to transformations not yet fully predictable. The most important forum of debate is still undefined, but pronounced activity in

${ }^{*}$ ) Trabalho elaborado como parte dos requisitos para obtenção do título de especialista em Direito Sanitário na Universidade de São Paulo.

${ }^{(* *}$ Médico e Advogado especialista em Direito Sanitário; Mestrando em Administração de Empresas pela EAESP-FGV. 
the World Trade Organization has been verified, unopposed by the World Health Organization. Developments in the next years could create a whole new framework to the sector. Every stakeholder group should be represented in such discussion.

\section{Keywords}

Globalization, Healthcare, WTO, WHO, International Law.

\section{INTRODUÇÃO}

Este trabalho assume algumas premissas como fundamentais, as quais serão abordadas com maior vigor no ponto adequado da discussão. São elas:

1. Existe um complexo fenômeno sócio-econômico-cultural, de alcance mundial, conhecido como "globalização", acontecendo em nossos dias.

2. Tal fenômeno tem implicações sobre todas as áreas da atividade humana, criando fatos e situações inéditas e modificando muitas das já existentes.

3. Implicaçĩes de tal fenômeno ocorrem tanto sobre o direito, nacional e internacional, quanto sobre a saúde.

4. Existe, como conseqüência da velocidade das transformações em ambos os c:ampos, um grande número de questões em aberto, criadas pelo surgimento de fatos inéditos, ressaltando a necessidade de adaptação do sistema jurídico internacional às novas realidades.

Entre as questões em aberto podemos destacar a dúvida quanto ao grau de liberalização do mercado privado de saúde, que ocorrerá nos próximos anos em nivel mundial; o quanto as organizações internacionais serão capazes de moldar esse processo, seja freando-o ou acelerando-o; se a liberalização dos mercados significará melhora ou piora nas condições de saúde, especialmente das populações mais pobres; qual será o foro de discussões a respeito e muitas outras.

As modificações estão aí. A Jamaica importa enfermeiras de Myanmar para suprir sua carência, visto que suas profissionais emigram em grande número para trabalhar nos Estados Unidos; planos de saúde do Texas credenciam hospitais do México; serviços de telemedicina localizados nos Estados Unidos atendem a demanda de países do Golfo Pérsico; agências de turismo alemãs oferecem pacotes de viagem para Cuba incluindo visita a praias e cirurgias; empresas chinesas instalam-se na Suiça para oferecer sua medicina tradicional; estudantes de medicina da Alemanha pagam cré- 
ditos de seus cursos em instituições de medicina tradicional chinesa em Beijing; seguradoras norte-americanas compram participações em empresas brasileiras; fundos de investimentos com participação estrangeira compram redes de laboratórios de diagnóstico médico em São Paulo, Rio de Janeiro e Belo Horizonte; exames de diagnóstico colhidos em Campinas são processados em Baltimore; redes internacionais de hospitais são constituídas, planos de saúde adquiridos em São Paulo oferecem cirurgias em Miami. Os exemplos são muitos. Mas como o direito sanitário internacional reage a todas essas modificações de nossa realidade cotidiana?

\section{GLOBALIZAÇÃO E SAÚDE}

Vicente Navarro, da Faculdade de Saúde Pública da Universidade John Hopkins, escreveu em 1998 um artigo no qual apresenta as características do chamado processo de globalização.

Segundo Navarro, durante os anos 80 uma nova ortodoxia econômica surgiu nos países ocidentais. Favorecida por vitórias conservadoras em várias eleições, principalmente com a subida ao poder de Ronald Reagan nos Estados Unidos e de Margareth Thatcher no Reino Unido, ela apresentava as seguintes crenças básicas:

- O déficit público é intrinsecamente negativo; o controle rigoroso da inflação através de políticas econômicas recessivas é prioritário.

- A regulação estatal do mercado de trabalho, protetora dos trabalhadores, também é intrinsecamente negativa.

- A proteção social garantida pelo Estado de Bem-Estar Social e suas políticas redistributivas prejudicam o crescimento econômico.

- Os Estados não devem intervir para regular o comércio internacional ou mercados financeiros internacionais.

Dessa forma, Navarro chama a atenção para alguns dos caracteres básicos da nova ortodoxia. Entretanto, vale notar que tais conceitos não são propriamente novos, trazendo em si as lições do filósofo inglês Adam Smith, para quem o vício da procura pela satisfação pessoal, se praticado de forma coletiva e livre, levaria à virtude do progresso de todos. A ligação entre os dois seria feita pela chamada "mão invisível do mercado", cabendo aos governos apenas assegurar a competição entre os agentes econômicos; além disso, tal ortodoxia repete práticas econômicas liberais dos governos do século XIX.

Ajudada pelo espetacular colapso do bloco socialista de nações na virada dos anos $80 / 90$, o agora chamado neoliberalismo tornou-se ideologia 
comum na formulação de políticas nacionais e internacionais. O fenômeno foi ainda amplificiado pelo desenvolvimento de novas tecnologias de informática e telecomunicações, as quais permitiram a ampliação dos espaços econômicos.

As políticas ditas "neoliberais" têm sido acusadas por seus críticos de gerarem estabilização monetária a um custo social muito alto, representado pelo aumento doss índices de desemprego, recessão econômica e acentuação de desiguadades sociais. Seus defensores contra-argumentam que os países mais ferozmente liberais, como os Estados Unidos, são os que exibem os melhores índices econômicos, e que as mazelas sociais atuais são temporárias e inevitáveis para preparar as economias para um crescimento "sustentável".

Paralelamente ao fenômeno econômico do ressurgimento das políticas liberais, vivemos os efeitos da maior interação cultural e social entre populações de diferentes países e regiões, decorrente do desenvolvimento de tecnologias de profundo impacto no cotidiano, tais como telecomunicações e informática. Mais uma vez há uma polarização da discussão. Os críticos do processo enxergam a destruição de culturas peculiares e a imposição de valores próprios dos países ricos, bem como a eliminação do próprio conceito de soberania estatal, substituída pelo interesse das grandes corporações multinacionais. Seus defensores vêem neste processo a ampliação das possibilidades de desenvolvimento humano, com maior acesso à educação, saúde e outras benesses.

De qualquer forma, vale notar que o impacto das modificações que vivemos atinge todos os estratos sociais, seja através de fatores positivos, como acesso a bens de melhor qualidade e preço, quanto a aspectos negativos, como a insegurança em relação ao trabalho.

Mesmo no âmbito da OMS as modificações são sentidas, e a resolução WHA48.16, de 1995, refere-se à necessidade de contínua evolução administrativa da O'ganização em resposta às modificações globais.

O fórum de discussão do assunto, como veremos, ainda está indefinido, não obstante a possibilidade de todo um novo desenho da assistência à saúde poder surgir. Não seria exagero supor que este será um dos maiores desafios do Direito Internacional Sanitário no começo do século.

\section{O DIREITO INTERNACIONAL SANITÁRIO}

O direito internacional sanitário está ligado historicamente à busca de segurança sanitária. Desde os primeiros documentos registrados sobre o assunto, produziclos em Veneza no século XIV, sobre regras de quarentena, 
até a criação da Organização Mundial da Saúde (OMS), cuja Constituição entrou em vigor em 1948, a ênfase foi a busca da maior proteção possível contra a disseminação das moléstias infecciosas associada à menor interferência possível com o fluxo internacional de bens e pessoas. A criação da OMS, ligada ao contexto histórico do pós-guerra, modificou significativamente este quadro, objetivando auxiliar a comunidade internacional a alcançar o mais alto nível possível de saúde, entendida como um direito humano fundamental. Além da OMS, outras organizações internacionais participam direta ou indiretamente da elaboração de políticas internacionais de saúde, tais como outras agências da Organização das Nações Unidas (UNICEF, UNDP, UNPF), Banco Mundial, Fundo Monetário Internacional e mais recentemente a Organização Mundial do Comércio.

A discussão em torno dos serviços de saúde ganhou importância a partir do final da década de 80 , quando a maior parte das nações desenvolvidas passou a buscar alternativas para os modelos vigentes de financiamento à saúde, cujos custos cresciam a taxas maiores que as taxas da inflação geral e que passaram a ameaçar sua estabilidade fiscal. Por fatores já citados previamente, deu-se um aumento da importância do sistema privado de saúde. Vale citar como exemplo o fenômeno do NHS britânico, sistema público universal de cobertura à saúde, sempre bem avaliado pela população. A despeito de tal fato, em editorial publicado no Lancet em 1999, é citado o impressionante dado de que $20 \%$ dos procedimentos cirúrgicos são atualmente realizados no sistema privado.

O crescimento do sistema privado de saúde, associado à internacionalização da economia, vem expondo um vácuo do sistema do Direito Internacional Sanitário, cujo preenchimento encontra-se em discussão. A exposição das políticas das diversas organizações internacionais envolvidas situará a discussão em seu contexto apropriado.

\section{ORGANIZAÇÃO MUNDIAL DA SAÚDE}

A Organização Mundial da Saúde, agência especializada da Organização das Nações Unidas, é regida por sua Constituição, que entrou em vigor em 7 de abril de 1948. Com sede em Genebra, Suiça, possui uma estrutura descentralizada, com seis Escritórios Regionais: África, Américas (Organização Panamericana de Saúde), Mediterrâneo Oriental, Europa, Sudeste Asiático e Pacífico Ocidental. Possui um "Escritório de Contatos" em Washington. Possui 191 membros, e um orçamento de aproximadamente 1,647 bilhão de dólares no ano de 1999. 
É definida por sua Constituição como sendo a "autoridade diretiva e coordenadora nos esforços internacionais relacionados à saúde". Tanto em seus objetivos quanto em seu "Mission Statement", inclui com clareza a assistência a governos para o fortalecimento de serviços de saúde. A mesma norma fundamental prevê que a ética deve prevalecer em todas as atividades da Organização; o conceito de ética está intimamente relacionado à idéia de eqüidade no acesso à saúde. A participação das comunidades é elevada à condição de princípio da Constituição da organização.

Em seus anos iniciais, a OMS mostrava uma abordagem orientada para o combate a doenças específicas, dominada por profissionais da área médica, com uma estratégia basicamente técnica.

Com o tempo, evidenciou-se o fato de que tal abordagem apresentava falhas. O fracasso do programa de erradicação da Malária foi um exemplo. Em meados da clécada de 70 a abordagem mudou, com políticas voltadas para a assistência básica da saúde reunidas sob o título de "Saúde para Todos", articuladas internacionalmente na Declaração de Alma Ata, de 1978, com ênfase no papel das comunidades e na relação entre saúde e desenvolvimento. A postura mais politizada da Organização persistiria pela década de 80 , mas, com a nomeação de Hiroshi Nakajima para o cargo de DiretorGeneral em 1988, a Organização assumiu novamente um caráter técnico. Críticas foram feitas ao fato dele ter sido diretor do departamento de pesquisas da Nippon Roche. Reeleito em 1993, seria substituído em 1998 pela exprimeira ministra da Noruega, a médica Gro Harlem Brundtland, após um segundo mandato no qual seria alvo de muitas críticas e mesmo de alegações de corrupção.

Reconhecendo a necessidade de mudanças globais, o processo de renovação do programa "Saúde para Todos" seria iniciado em 1995. Nos documentos relacionados ao programa "Saúde para Todos no século XXI", é citada uma lista de "parceiros" da OMS no processo: o setor privado, as organizações de Bretton Woods, a Organização Mundial do Comércio, a comunidade acadêrnica, as Organizações Não Governamentais e as demais agências da ONU. A resolução WHA51.7 acrescenta um anexo ao artigo 23 da Constituição da OMS, em cujo inciso III lê-se: "... We will continue to develop health systems to respond to the current and anticipated health conditions, socioecoriomic circumstances and needs of the people, communities and countries coricerned, through appropriately managed public and private actions and investments for health".

Embora não haja uma política específica para o sistema privado de saúde, nota-se, nos documentos da Organização, a tolerância de sua existência e a tentativa de submetê-la a seus princípios éticos.

A Constituição da OMS entrou em vigor no dia 7 de abril de 1948, após vinte e seis Membros terem depositado os instrumentos de aprovação junto à Secretaria-Geral da ONU. 
A análise da Constituição revela de imediato a tensão inerente a qualquer organização internacional: por um lado há necessidade de rapidez na tomada de decisões e implementação de medidas; por outro lado, as preocupações dos membros com sua soberania impedem que existam mecanismos suficientemente adequados para que tal agilidade seja alcançada. Muitas decisões são postergadas por falta de consenso entre os membros. A opção da Organização por recomendações de ordem técnica, ou orientações de cunho político vago, evidenciam essa dificuldade.

A OMS pauta suas políticas pela necessidade de uma distribuição equânime dos recursos da saúde, com preocupação pelos mais carentes. Na elaboração de suas políticas, não distingue entre os setores privado e público, considerando que ambos devem seguir os mesmos princípios gerais.

A Organização pauta sua política por quatro princípios básicos:

1. Integração entre saúde e desenvolvimento humano nas políticas públicas.

2. Garantia de acesso equânime aos serviços de saúde.

A organização ressalta o conceito de "serviços primários de saúde", entendidos como os cuidados essenciais de saúde, baseados em métodos e tecnologias práticos, científicos e socialmente aceitáveis, universalmente acessíveis a indivíduos e famílias através de sua participação ativa e custos ao alcance da comunidade e do país. Na visão da OMS, é a função central e principal foco de atenção do sistema de saúde de um país, o primeiro elemento de um processo continuado de cuidados com a saúde.

Baseia-se em oito elementos:

- educação sobre os problemas prevalentes de saúde e sobre os métodos de preveni-los e controlá-los;

- provisão de adequados suprimentos de alimentos e nutrição adequada;

- suprimento adequado de água e saneamento básico;

- cuidados com as crianças e com as mães, incluindo-se planejamento familiar;

- imunização contra as principais doenças infecciosas;

- prevenção e controle de doenças endêmicas;

- tratamento adequado de doenças e lesões comuns e

- fornecimento de medicamentos essenciais. 
Essa posição da Organização, exposta em seu site, sugere a existência de um limiar mínimo de cuidados públicos de saúde, permitindo a interpretação de uma aceitação da participação do setor privado nos demais níveis de atendimento.

3. Promoçäo e proteção da saúde.

4. Prevenção e controle de problemas específicos.

A definição básica das políticas da organização está em seu programa "Saúde para Todos no Século XXI".

A respeito do programa, a Assembléia da OMS publicou a resolução WHA 51.7, em 16 de maio de 2000, com força de recomendação, cujo texto, em seu Título III, estabelece que "... continuaremos a desenvolver sistemas de saúde para responder às atuais e também às vindouras condições de saúde, circunstâncias sócio-econômicas e necessidades dos povos, comunidades e países envolvidos, através de ações públicas e privadas apropriadamente administradas, e de investimentos em saúde".

Assim podemos fazer as seguintes observações a respeito das posições da OMS no quadro institucional de crescimento do setor privado de saúde:

- A organização pauta sua política pela orientação geral a respeito de saúde, com preocupação com a eqüidade no acesso aos serviços de saúde e recomendando aos governos um mínimo na figura dos "Cuidados básicos de saúde".

- A organização implicitamente reconhece a existência e importância dos serviços privados de saúde, sem entretanto traçar diretrizes específicas quanto às políticas a serem seguidas pelos governos a esse respeito, o que de resto é compreensível, dado o escopo científico normalmente associado à organização.

- A forma rnais eficaz de intervenção da Organização dá-se na forma de recomendações, visto que o processo negocial dificultoso a que estão submetidas outras figuras jurídicas de intervenção inibem sua utilização.

Duas declarações recentes da Diretora-Geral, Dra Gro Harlem Brundtland, esclarecem sobremodo as posições da Organização:

Em sua conferência "Por que investir em saúde global é uma boa política", junto ao Conselho de Relações Exteriores, em Nova York, a Diretora-Geral tocou em vários pontos relevantes para o esclarecimento das posições da Organização quanto à globalização. A conferência foi realizada no último dia 6 de dezembro. O Conselho é uma instituição norte-ame- 
ricana, privada, sem fins lucrativos, conhecida por publicar a revista "Foreign Affairs".

Destacam-se, no discurso da Diretora-Geral, os seguintes pontos:

"A separação entre problemas nacionais e internacionais está perdendo sua utilidade à medida que pessoas e bens viajam através dos continentes.

... Dois anos atrás, o Instituto de Medicina da Academia Nacional de Ciências [dos EUA] produziu um relatório pequeno mas importante, "O interesse vital dos EUA na saúde global", com a seguinte trilogia: 'proteger nosso povo; estimular nossa economia; promover nosso interesse nacional'. Fez forte defesa de por que os EUA serão beneficiados se investirem em saúde no exterior".

Continua a Dra Brundtland:

"Isto leva ao segundo argumento: ganho econômico. Existem razões morais e éticas pelas quais os EUA e outros países desenvolvidos deveriam investir no combate à epidemia global de AIDS que está se acelerando no Sul da África - ou unir forças para interromper a disseminação da tuberculose e unir-se a nós no programa Rolling Back Malária. Mas além destes argumentos existe a lógica econômica que devemos desenvolver e comunicar de forma mais convincente. Existe $o$ argumento óbvio de que populações mais saudáveis no exterior formariam melhores mercados para os bens e serviços norte-americanos. De forma crescente em uma economia globalizada, a pobreza de uma região é a oportunidade perdida de outra. Quanto mais próspero o resto do mundo for, maiores serão os ganhos para os Estados Unidos.

Além disso, os serviços de saúde em si tornaram-se uma vasta indústria global, absorvendo em 1994 cerca de $9 \%$ da produção mundial, ou 2,3 trilhões de dólares. Eu não preciso lembrar a audiência sobre a centralidade da saúde em sua economia. Com os gastos em saúde aproximando-se de um trilhão de dólares por ano, ou 15\% do PIB - um recorde mundial - sabe-se muito bem que os serviços de saúde têm efeitos em váriáveis macroeconômicas centrais, como emprego, inflação e capacidade para competir nos mercados globais".

"O envolvimento do setor privado é absolutamente necessário. Mas não há forma de substituir um forte compromisso do setor público com a saúde global - através de investimentos, pesquisa e atenção política. Novamente, examinemos as negociações no âmbito da Organização Mundial do Comércio - que tratam da construção de um sistema regulatório que corresponda à realidade de uma economia global. Trata-se de estender a democracia e o império da lei a outro nível - nível 
global. E ao lado disso está a necessidade crucial de promover certos bens públicios globais - e a saúde é um bem crítico".

Em outra palestra, intitulada "Acordos Internacionais de Comércio e Saúde Pública", proferida na "Conferência sobre Facilitação do Acesso aos Medicamentos Essenciais em uma Economia Globalizada" (realizada em Amsterdã, em 26 de novembro de 1999), a Dra Brundtland fez uma série de declarações, que embora relacionadas a medicamentos, também esclarecem a postura da Organização quanto à globalização:

"Protecionismo nunca beneficiou a saúde pública. A OMS estimula os governos a adotarem legislações que obtenham vantagem de um comércio mais aberto e de um sistema internacional melhor regulamentado. E nós apoiamos os governos que incorporarem salvaguardas construídas sob o acordo TRIPS (sobre propriedade industrial) da Organização Mundial do Comércio visando proteger o público.

... acordos comerciais não devem criar restrições ao comércio. Um princípio importante da OMS é que regulamentos técnicos, padrões e procedimentos devem ser baseados em recomendações, padrões e orientações internacionais".

Fica clara nestas declarações a posição da OMS como agência que pretende fornecer o substrato técnico para discussões sobre saúde, bem como orientação estratégica para os serviços públicos de saúde. E é possível a interpretaçäo de que, ao menos implicitamente, reconhece a competência da OMC para legislar sobre os aspectos econômicos da saúde, especialmente do setor privado.

\section{A ORGANIZAÇÃO MUNDIAL DO COMÉRCIO}

Conhecida pela sigla OMC, constitui-se em uma organização governamental cujas origens remontam ao final da Segunda Guerra Mundial. Embora seu objetivo esteja relacionado à negociação de acordos na área do comércio internacional, veremos que sua atuação está intimamente relacionada à internacionalização dos serviços de saúde. Recentemente a organização foi alvo de intensos protestos, quando da reunião ministerial realizada na cidade norte-americana de Seattle. Embora o fracasso das negociações tenha levado muitos órgãos da imprensa mundial a "decretarem" o fim da Organização, é pouco provável que tal ocorra. A compreensão de suas origens, sua estrutura, mecanismo de furicionamento e política para a área da saúde é essencial para a compreensão das transformações que vivemos.

Em 1944, em Bretton Woods, Estados Unidos, foi concluído um acordo com o objetivo de criar aquele que seria o arcabouço financeiro internacional do pós-guerra, constituído por três instituições: 
1. Fundo Monetário Internacional (FMI) - com o objetivo de manter a estabilidade das taxas de câmbio e ajudar os países com problemas nas balanças de pagamentos.

2. Banco Mundial ou Internacional - para a reconstrução e desenvolvimento, com a função de fornecer os capitais necessários para a reconstrução dos países atingidos pela guerra

3. Organização Internacional do Comércio - com a função de coordenar e supervisionar a negociação de um novo regime para o comércio mundial baseado nos princípios do multilateralismo e do liberalismo. A OIC nunca saiu do papel, em parte pelo fato de os EUA nunca terem ratificado a carta de Havana que criava a instituição; as razões da não-ratificação pelo Congresso dos Estados Unidos estavam relacionadas ao temor dos seus com o comprometimento da soberania do país.

A solução do impasse veio através da negociação de um acordo provisório, em 1947, entre 23 países, que adotava apenas um segmento da Carta, relativo às negociações de tarifas e regras sobre o comércio. Passou a ser chamado de GATT (General Agreement on Tarifs and Trade) - Acordo Geral sobre Tarifas e Comércio). De fato, ainda que não de Direito, o GATT transformou-se em uma organização internacional, com sede em Genebra, coordenadora e supervisora das regras do comércio até o final da Rodada Uruguai.

As negociações aconteciam em diferentes etapas, conhecidas como rodadas, a última das quais se encerrou em 1994. O sucesso da empreitada fica nítido quando se observa que, em 1947, a média das tarifas aplicadas era de $40 \%$, e, em 1994 , era de $5 \%$. O número de participantes aumentou de $23 \mathrm{em} 1947$ para $123 \mathrm{em}$ 1994. Um dos principais temas negociados na Rodada Uruguai foi a criação da OMC, que substituiu o GATT. Ela pretende ser a coluna mestra do novo sistema internacional do comércio. Só podem ser membros da OMC os participantes que aceitam todos os acordos como um conjunto não dissociável (single undertaking).

A organização tem quatro funções básicas:

1. facilitar a implementação, a administração, a operação, bem como levar adiante os objetivos dos acordos da Rodada Uruguai;

2. constituir um foro para as negociações das relações comerciais entre os Estados-membros, com o objetivo de criar ou modificar acordos multilaterais de comércio;

3. administrar o Entendimento (undestanding) sobre Regras e Protocolos Relativos às Soluções de Controvérsias, isto é, administrar o "tribunal" da OMC; 
4. administrar o Mecanismo de Revisão de Políticas Comerciais com o objetivo cle fazer revisões periódicas das Políticas de Comércio Externo de todos os membros da OMC, apontando os temas que estão em desacordo com as regras negociadas.

Muitas são as formas de influência da OMC sobre os sistemas privados de saúde, destacando-se o GATS: trata-se do Acordo geral sobre o Comércio de Serviços, que tem como objetivo estabelecer um quadro de referência multilateral de princípios e regras para o comércio de serviços, com vistas à sua expansão, sob condições de transparência e progressiva liberalização, e como meio de promoção do crescimento econômico de todos os parceiros comerciais.

Possui três princípios básicos:

1. Cobrir todos os serviços internacionais, exceto aqueles providos pelas autoridades governamentais. Inclui:

- serviços fornecidos de um país a outro (ex.: telemedicina);

- consumidores ou empresas fazendo uso de serviços em outro país (ex.: viagens para tratamento médico; manutenção de equipamento hospitalar em outro país);

- empresa estrangeira estabelecendo-se em outro país para fornecimento cle serviços (ex.: seguradoras, administradoras de planos de saúde);

- pessoas viajando para outros países para fornecimento de serviços (ex.: consultorias internacionais na área de saúde).

2. Não deve haver favorecimento de provedores nacionais de serviços em relação a estrangeiros. O GATS aplica-se apenas aos pontos em que haja comprometimento do governo

3. Não deve haver discriminação entre os membros de diferentes países - conhecido como princípio da cláusula da nação mais favorecida ("favoreceu a um, deve favorecer igualmente a todos"). Em princípio, os governos podem estabelecer exceções, por no máximo dez anos.

Em nota publicada em 18 de setembro de 1998, intitulada "Serviços de Saúde e Sociais", a OMC marca sua posição em relação ao assunto, destacando-se:

a) crença na liberalização econômica do setor serviços de saúde, com abertura ao capital externo como forma de otimização da alocação de recursos;

b) questionamento da posição que sustenta serem os serviços de saúde bens não comercializáveis. 
c) cita o fato de que, "em 1996, exportações americanas em serviços de saúde, principalmente na forma de tratamento a turistas estrangeiros durante suas estadias no país - atingiram a cifra de U\$872 milhões, enquanto as importações atingiram cerca de U\$550 milhões. (...) Embora a maior parte dos pacientes adoeça enquanto visitam os Estados Unidos, algumas instituições médicas de ponta como Mayo Clinics, John Hopkins Medical Center e Massachusetts General Hospital atraem quantidades significativas de pacientes que viajam para serem tratados (as quatro Mayo Clinics esperavam 10.000 pacientes estrangeiros em 1997). O Departamento de Comércio dos Estados Unidos enxergam um mercado crescentemente promissor na América Latina, ressaltando que se estima em $\cup \$ 60$ milhões o gasto anual dos argentinos em tratamento médico no exterior, e que mais de 400.000 mexicanos poderiam pagar por tratamento médico nos Estados Unidos".

Em um trabalho publicado no Lancet em 1999, o professor inglês David Price critica a posição da OMC a partir dos seguintes pontos:

a) muitos governos, estimulados pela OMC, estariam privatizando 0 financiamento e o provimento de serviços públicos, sem adequado debate público;

b) as corporações transnacionais têm assento nos comitês de aconseIhamento da organização, estabelecendo a agenda, ao menos em parte;

c) as corporações multinacionais estariam reivindicando a abertura dos mercados referentes aos serviços de saúde, com o apoio da $\mathrm{OMC}$ e do Banco Mundial;

d) a OMC teria três objetivos principais: "estender a cobertura do GATS, endurecer os procedimentos para solução de controvérsias de maneira a facilitar o enquadramento dos membros em suas determinações e modificar as regras de compras dos governos para criar acesso aos mercados [que eles representam]";

e) a rodada anterior de negociações ministeriais (rodada Uruguai) permitiu aos governos protegerem a saúde e os serviços sociais do tratamento previsto no GATS definido-os como serviços governamentais, através de seu artigo 1.3: 'serviço governamental é aquele que não é provido em uma base comercial, nem em competição com outros provedores'. O artigo 19 do GATS, entretanto, objetiva terminar com tal proteção: 'membros devem entabular negociações... objetivando atingirem um grau progressivo de liberalização";

f) o secretariado da OMC tem argumentado que para serviços serem classificados sob o artigo 1.3 eles devem ser totalmente gratuitos. "(...) Portanto, de acordo com a OMC, onde quer que haja uma mistura de 
financiamento público e privado... o setor de saúde deve ser aberto às corporações internacionais".

A visão proporcionada tanto pelo texto da $\mathrm{OMC}$ quanto pela crítica do Prof. Price revelam as complexidades da questão, evidenciando mais uma vez a necessidade de que qualquer modificação do sistema jurídico internacional no que concerne à saúde deva ter sempre como objetivo imediato o benefício dos seres humanos e que deva ser precedida de amplo debate na sociedade

\section{CONCLUSÃO}

O fenômeno da globalização vem criando toda uma nova série de fatos no âmbito dos serviços de saúde, para os quais o direito positivo da maior parte dos países não se encontra preparado. Além disso, a chamada "crise da assistêricia à saúde", caracterizada por crescentes despesas nacionais com o setor, forneceu o contexto adequado para o crescimento do setor privado em quase todo o mundo. A participação das grandes corporações transnacionais é cada vez maior.

O Direito Internacional do setor encontra-se em construção. O foro de discussões no momento parece ser a OMC, com a OMS limitando-se a orientações prograrnáticas e de princípios. O momento é de grande importância, pois discussöes como aquelas envolvendo o GATS, a legislação nacional do setor, o papel da OMS e outras correlatas poderão moldar o arcabouço jurídico de um sistema internacional de saúde por décadas. Mais do que nunca, a participação dos setores organizados da sociedade civil nacional e internacional e o meio acadêmico devem participar ativamente do processo, procurando direcionar o vetor resultante desta discussão para a preocupação com o ser humano.

Embora o setor privado seja movido pela lógica do lucro, a resposta da sociedade aos seus movimentos provavelmente exercerá sobre ele um feedback capaz cle transformá-lo e direcioná-lo, pelo menos em certo grau. $E$ é o próprio discurso da racionalidade econômica que fornecerá os elementos para efetivação dessas transformações, principalmente através do desenvolvimento acadêmico e jurisprudencial de dois setores da ciência jurídica:

a) o estudo dos direitos do consumidor, permeado pela consciência de que o primeiro direito do consumidor é ser respeitado em seus direitos fundamentais de ser humano, contrapondo-se à idéia de efficientia gratia efficientia que parece tão grata à cartilha neoliberal, onde muitas vezes se buscam números e não resultados sociais; 
b) o desenvolvimento dos estudos sobre direito antitruste da saúde, visando impedir a constituição de oligopólios no setor, contrapondose ao argumento neoliberal de que os mercados devem ser livres, sendo que muitas vezes essa suposta "liberdade" é utilizada para a concentração do poder econômico no vácuo deixado pelo Estado em retirada.

A lógica da competição econômica fornece estes dois instrumentos jurídicos poderosos para a defesa da população contra os abusos do poder econômico, dando ao direito à saúde sua devida proteção, sem esquecer jamais que esta é o "estado de completo bem-estar físico, psíquico e social, e não apenas a ausência de doença" - e muito menos uma mercadoria.

\section{BIBLIOGRAFIA}

BEAGLEHOLE, R. e BONITA, R. "Public Health at the Crossroads - Achievements and prospects", Cambridge, Cambridge University Press, 1997.

BERSTEIN, A. B. e GAUTHIER, A. K. "Definig Competition in Markets: Why and How?". Health Services Research, 1998; 33:5.

Black's Law Dictionary. $7^{\text {a }}$ edição, St. Paul, Minn, West Group, 1999.

FARIA, J. E. "O Direito na Economia Globalizada", São Paulo, Malheiros, 1999.

FIDLER, D. "International Law and Infectious Diseases", Oxford, Clarendon Press, 1999.

FOLLAND, S., GOODMAN, A., STANO, M. "The Economics of Health and Health Care", New Jersey, Prentice-Hall, 1997.

GLIED, S. "Managed Care"; Working Paper Series - National Bureau of Economic Research, Cambridge, 1999.

KOIVUSALO, M. e OLLILA, E. "Making a Healthy World", New York, Zed Books, 1997.

KUTTNER, R. "The American Health Care Syistem - Wall Street and Health Care", New England Journal of Medicine, 1999; 340:664-667.

Lancet (1999), suplemento do milênio.

LE GRAND, J. "Competition, Cooperation, or Control? Tales From the British National Health Service", Health Affairs, May/June 1999; 18: 27-39.

LUTZ, S., GROSSMAN, W., BIGALKE, J. "Med. Inc. - How Consolidation Is Shaping Tomorrow's Healthcare System", San Francisco, Jossey-Bass Publishers, 1998. 
NAVARRO, V. "Neoliberalism, Globalization, Unemployment, Inequalities, and the Welfare State", International Journal of Health Services 1998; 28: 607682.

NAYLOR, D. C. "Health Care in Canada: Incrementalism Under Fiscal Duress", Health Affairs, May/June 1999, 18:9-25.

HAAS-WILSON, D. e GAYNOR, M. "Increasing Consolidation in Healthcare Markets: What Are the Antitrust Policy Implications?", Health Services Research 1998; 33: 1403-19.

HENSLEY, S. "Brazilian Healthcare at Crossroads", Modern Healthcare, 17 de Maio, 1999, 34-37.

Organização Mundial do Comércio. "Health and Social Services", Background Note by the Secretariat - Council for Trade in Services - Genebra, 1998.

PECKHAM, M. "Developing the National Health Service: a model for public services", Lancel 1999; 354:1539-45.

PRICE, D. "How the World Trade Organization is Shaping Domestic Policies in Health Care", Lancet, 1999; 354: 1889-92.

REZEK, J. F. "Direito Internacional Público", São Paulo, Saraiva, 1998.

SOARES, Guido F. S. "Aspectos Internacionais da Segurança Sanitária".

Texto da palestra proferida durante o Seminário Internacional de Direito Sanitário, São Paulo, 1999.

SIDDIQI, J. "World Health and World Politics", Columbus, University of South Carolina Press, 1995.

THORSTENSEN, V. "OMC - Organização Mundial do Comércio - As Regras do Comércio Internacional e a Rodada do Milênio", São Paulo, Aduaneiras, 1999.

ZARRILI, S. e KINNON, C. "International Trade in Health Services - a development Perspective", Genebra, UNCTAD/OMS, 1999. 